\title{
Part II: Checkpoint inhibitors in cancer therapy
}

\author{
"These reviews emphasize both the enormous distance traveled \\ in the last few years and the gaps in our knowledge of immune \\ checkpoint inhibition."
}
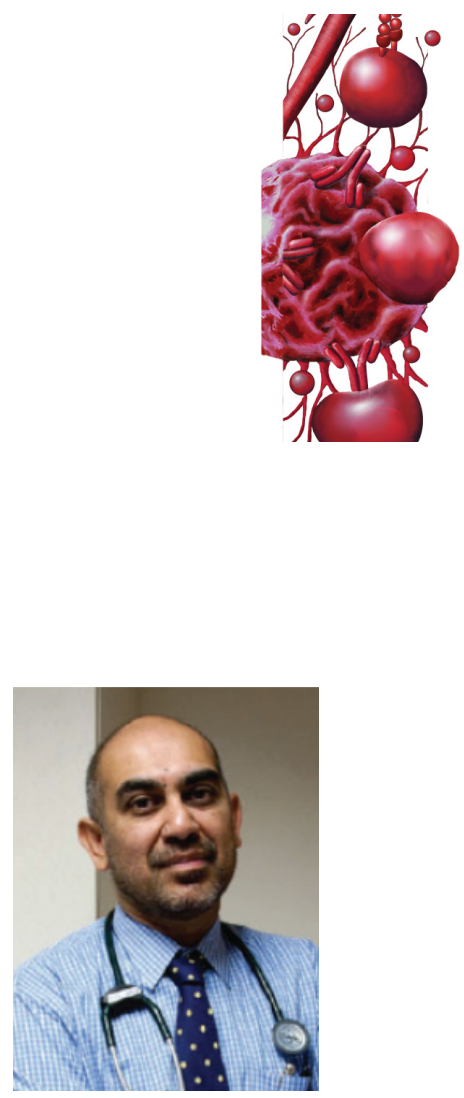

Adil I Daud

University of California, 1600 Divisadero St, San Francisco, CA 94143, USA Adil.Daud@ucsf.edu
Financial \& competing interests disclosure A Daud is consultant to Merck, Genentech, Pfizer, Roche, OncoSec and BMS. The author has no other relevant affiliations or financial involvement with any organization or entity with a financial interest have their own unique and distinctive spectrum of side effects. These vary by organ site and by the specific pathway inhibited and the specific agent used as described in an extensive review by Kourie and Klastersky [4]. Immune checkpoint inhibitors show (unexpected) activity in lung cancer and in hematological malignancies. The spectrum of activity in lung cancer extends to both squamous and adenocarcinoma subtypes and has its distinctive organ-specific characteristics and an emerging pattern with regard to PD-L-1 as described by Janakiram et al. in the next article [5]. These authors also describe the interesting observation that Hodgkin's disease appears to be very sensitive to PD-1 and the exploratory work in other hematologic malignancies. Last, but certainly not the least is a thought-provoking overview of immune checkpoint inhibitors by Kyi and Postow [6]. Given the activity seen in numerous locations and the emerging combinations being tested, these authors place these developments in context and provide an extensive bibliography for readers to explore. These reviews emphasize both the enormous distance traveled in the last few years and the gaps in our knowledge of immune checkpoint inhibition.

in or financial conflict with the subject matter or materials discussed in the manuscript apart from those disclosed.

No writing assistance was utilized in the production of this manuscript.

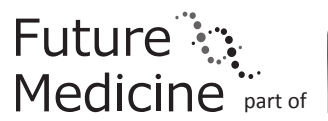




\section{References}

1 Eder J, Stahl M, Gedrich R, LaVallee T, Peck R. Targeting KIT on innate immune cells to enhance the antitumor activity of checkpoint inhibitors. Immunotherapy $8(7)$, 764-774 (2016).

2 Loo K, Daud A. Emerging biomarkers as predictors to anti-PD1/PD-L1 therapies in advanced melanoma. Immunotherapy 8(7), 775-784 (2016).

3 Zibelman M, Ghatalia P, Geynisman D, Plimack E. Checkpoint inhibitors for renal cell carcinoma: current landscape and future directions. Immunotherapy $8(7)$, 785-798 (2016).
4 Kourie HR, Klásterský JA. Immune checkpoint inhibitors: side effect and management. Immunotherapy 8(7), 799-807 (2016).

5 Janakiram M, Pareek V, Cheng H, Narasimhulu DM, Zang $\mathrm{X}$. Immune checkpoint blockade in human cancer therapy: lung cancer and hematologic malignancies. Immunotherapy 8(7), 809-819 (2016).

6 Kyi C, Postow MA. Immune checkpoint inhibitor combinations in solid tumors: opportunities and challenges. Immunotherapy 8(7), 821-837 (2016). 